\title{
Arbor
}

\section{Tecnología y Sociedad. La nueva tarea del héroe}

\section{Daniel Martín Mayorga}

Arbor CLXXV, 690 (Junio 2003), 1019-1035 pp.

\section{Tecnología y Sociedad de la Información ${ }^{1}$}

La sociedad de la información, sobre todo antes del pinchazo de la burbuja, estuvo muy de moda como concepto, tema de reflexión o debate y argumento de artículos y libros. Ha tenido excelsos apologistas y, por supuesto, celosos detractores. Y entre medias, una legión de analistas y estudiosos atraídos por su evidente importancia como fenómeno social y económico. Veamos algunos ejemplos:

Una visión idealista (por no decir ingenua):

"Sociedad que crece y se desarrolla alrededor de la información y aporta un florecimiento general de la creatividad intelectual humana, en lugar de un aumento del consumo material«. Yoneji Masuda, La sociedad informatizada como sociedad post-industrial. Editorial Tecnos, 1994.

Otra visión, impecable en su estilo tecnocrático y funcionarial:

«El término Sociedad de la Información se refiere a una forma de desarrollo económico y social en el que la adquisición, almacenamiento, procesamiento, evaluación, transmisión, distribución y diseminación de la información con vistas a la creación de conocimiento y a la satisfacción de las necesidades de las personas y de las organizaciones, juega un papel central en la actividad económica, en la creación de riqueza y en la definición de la calidad de vida y las prácticas culturales de los ciudadanos«. Libro verde sobre la Sociedad de la Información, 1997.

Una definición más reflexiva y matizada, con resonancias sociológicas: 
"Nuevo sistema tecnológico, económico y social en el que el incremento de productividad no depende del incremento cuantitativo de los factores de producción (capital, trabajo, recursos naturales), sino de la aplicación de conocimientos e información a la gestión, producción y distribución, tanto en los procesos como en los productos«. Manuel Castells, La era de la información. 1998.

Y una última, sacada de una página antisistema de Internet:

«Colusión entre la economía y la tecnología»

Hay otra, incompleta pero útil a nuestros propósitos, porque se refiere a las causas - tecnológicas en este caso- del fenómeno:

"Se puede decir que la sociedad de la información existe desde que están disponibles, conjuntamente, redes de comunicación de alcance planetario y sistemas potentes de procesamiento de información».

La sociedad de la información es todavía muy joven. Tanto, que se suele considerar 1995, cuando Internet salió de los laboratorios a comerse el mundo, como el año de su nacimiento. Pero la criatura crece deprisa. Precisamente ahora estamos en un momento especial, donde se dan las condiciones técnicas para considerar que el fenómeno está maduro.

Son suficientemente conocidas las siglas UMTS, que corresponden en inglés al sistema universal de telefonía móvil. Es la también llamada tercera generación celular, un salto tecnológico superador de la primera generación (analógica) y de la segunda (digital; el GSM que a todos nos acompaña en su versión convencional, o avanzada que permite conmutación de paquetes y se conoce como GPRS).

El UMTS ha adquirido notoriedad sobre todo por su importancia respecto a la mentada burbuja tecnológica. Pero la trascendencia tecnológica del UMTS es que cierra el círculo tecnológico de, digamos, la modernidad. Porque las tres columnas que sustentan el edificio de la sociedad de la información son Internet, banda ancha y movilidad. Internet, como protocolo universal, el lenguaje que todos los equipos y plataformas del próximo futuro van a usar para comunicarse entre sí. La banda ancha, que en términos técnicos equivale a un mínimo de $2 \mathrm{Mbps}$ (2 millones de unidades de información por segundo) es la garantía de que los ingentes volúmenes de datos que enviamos o recibimos se cargan y descargan a velocidades aceptables. Y, finalmente, la movilidad, o posibilidad de intercambiar información en cualquier lugar en el que nos encontremos. En otras palabras, la personalización de los servicios.

Como Internet ya está, y la banda ancha se consiguió hace tiempo en las conexiones alámbricas, era necesario integrar la movilidad para 
completar el dibujo. Y es el UMTS quien lo logra, al permitir por primera vez velocidades de transmisión iguales o superiores a la barrera de los 2 Mbps. Podemos decir, en términos prácticos, que más no se le puede pedir a la tecnología de comunicación: proporcionar soluciones estándar de alta capacidad, disponibles en cualquier parte. Y esto abre paso a una nueva era.

Así pues, la Sociedad de la Información, partiendo de fundamentos tecnológicos muy sólidos, nos debería ofrecer un futuro abierto a la confianza. Pero, ¿se percibe esto así por el común de los ciudadanos?.

\section{La percepción social de la Tecnología}

En una sociedad tan tradicionalmente distante de la ciencia y la tecnología como la española — no por nada somos el país del «que inventen ellos»- este debate no se plantea demasiado (por indiferencia) o se plantea negativamente. Pero a escala mundial no es así. La relación de la ciencia y la sociedad como estudio específico interdisciplinario han tenido un gran auge desde la segunda mitad del siglo XX. Siglas como CTS (Ciencia, Tecnología y Sociedad; STS en inglés) se han acuñado para identificarla. $Y$ ha nacido una nueva rama del pensamiento filosófico, la llamada filosofía de la tecnología, que ha acumulado un amplio bagaje en pocos años. Todo un reconocimiento de la profunda interrelación entre estas disciplinas y su gran impacto en el modo de vida de las sociedades avanzadas.

CTS nació a principios de los 70 para agrupar todas las corrientes de investigación, principalmente académicas, pero también de fundaciones e instituciones públicas, relacionadas en sentido amplio con el impacto social de la ciencia y la tecnología. A estas alturas, es muy generosa la relación de temas que entrarían bajo el extenso paraguas de CTS:

- percepción pública de la ciencia y la tecnología.

- impacto social de la ciencia, tecnología e innovación.

- educación: formación de una cultura científico-técnica, capacitación de profesores.

- cuestiones éticas asociadas al progreso científico y tecnológico

- problemas medioambientales derivados de la tecnología, desarrollo sostenible.

- procesos de modernización tecnológica en las administraciones públicas. e-government. 
- participación ciudadana en las decisiones científico-tecnológicas

- análisis de la información (prensa, radio, TV) sobre temas científico-tecnológicos.

- asesoría técnica en políticas sobre el fomento de la innovación.

- evaluación de la funcionalidad de herramientas tecnológicas en entornos sociales predefinidos (p.e., discapacitados)

- responsabilidad corporativa de las empresas tecnológicas

CTS, como se puede ver, es una bisagra entre dos mundos que se necesitan, aunque en ocasiones se hayan dado la espalda. A finales de 2001 se publicaron los datos de un Eurobarómetro denominado Europeos, Ciencia y Tecnología, donde entre otras conclusiones se aseguraba que apenas el $45 \%$ de los encuestados mostraban interés por estos temas, mientras un porcentaje muy alto $(75 \%)$ se consideraba mal informado al respecto ${ }^{2}$.

Además de CTS, otra novedad que nos han traído los últimos tiempos la escena académica es la ya mencionada filosofía de la tecnología. Igualmente, es una disciplina con menos de medio siglo de vida, aunque tiene antecedentes en los múltiples análisis filosóficos o sociológicos de la técnica que a lo largo de la historia del pensamiento se han dado. Pensemos en nuestro Ortega y Gasset y su Meditación de la Técnica, obra de 1933 o en Jacques Ellul ${ }^{3}$ o Martin Heiddeger ${ }^{4}$, por citar sólo los más nombrados.

El arranque del filosofar sobre la tecnología surge de la superación de la identificación radical entre ciencia aplicada y tecnología, habitual en el empirismo y apoyada por filósofos de la ciencia tar relevantes como Mario Bunge. Actualmente, este planteamiento se considera limitado, porque el pensamiento tecnológico ha seguido en muchos casos su propio camino e incluso ha dado la vuelta: tecnologías como las de la telecomunicación e informática han servido para modular o modificar planteamientos científicos. Lo que justifica una reflexión independiente, enfocada a las cuestiones específicas de la tecnología.

Suele considerarse una doble tradición en la filosofía de la tecnología:

1) la humanística, clásica y de raíces históricas. Considera la tecnología con interés equivalente al que aplica a otros saberes, y reflexiona sobre sus aspectos sociales, éticos, epistemológicos o políticos. Ortega, en el libro citado, nos proporciona un buen ejemplo: la tecnología como una circunstancia más del hombre, como uno de sus rasgos constitutivos. No obstante, el verdadero consolidador de esta escuela es el norteamericano Lewis Mumford (1895-1988). En su libro más conocido, Te- 
chnics and Civilization ${ }^{5}$, de 1934, al dividir la historia en tres periodos -eotécnico (artesanal), paleotécnico (revolución industrial) y neotécnico (contemporáneo) - presenta un camino positivo de evolución que culmina en el triunfo de la ciencia. Es una visión optimista del potencial de la ciencia para mejorar la condición de vida de los seres humanos, pero precavida, pues recela del uso autoritario de la tecnología (en su nomenclatura, la monotécnica) y aboga por una politécnica o técnica democráticamente dirigida y controlada. Tras Mumford, otros muchos autores han seguido su estela, de manera que hoy se puede decir que la tradición humanística es la actualmente imperante, con seguidores en su mayoría de procedencia estadounidense. Quizá el más conocido es Carl Mitcham especialmente por su obra Thinking through Technology. The Path between Engineering and Philosophy (1994), un verdadero manual de esta naciente disciplina, donde se recorre su historia y se plantean y examinan los principales contenidos propios y relacionados.

2) la segunda escuela es la de los ingenieros. Corresponde sobre todo a la tradición germana, y su análisis parte de la realidad tecnológica preexistente (que no cuestiona) para examinar las consecuencias de su aplicación. Es, pues, esencialmente positivista. Como iniciador de esta tendencia habría que situar a Ernst Kapp (18081896), filósofo de la izquierda hegeliana que acuñó el término filosofía de la técnica. Su principal obra, Grundlinien einer Philosophie der Technik (1877), es quizá el primer tratado sistemático de esta nueva disciplina. Considera los mecanismos y aparatos que la técnica inventa como proyecciones de los órganos del cuerpo humano, cuyo fin es ayudarnos a superar nuestras limitaciones frente a la naturaleza y sus desafíos. Otros conocidos precursores son Friedrich Dassauer (1881-1963), también alemán neokantiano, que arrancando de un análisis metafísico de la técnica, concluye en una teoría místico-religiosa en la que asemeja los logros tecnológicos con la creación divina; y P. K. Engelmeier, ingeniero ruso cuya visión de la tecnología como motor del desarrollo de la Humanidad le lleva a relacionar ésta con el resto de las disciplinas, sobre la base de la racionalidad y del sentido de progreso que precisamente representa más que ninguna otra.

Con este paso rápido sobre CTS y la filosofía de la tecnología hemos oteado el panorama desde arriba. Está claro que el mundo académico en general y los estudiosos de la sociedad en particular, no podían quedarse indiferentes ante la inmensa transformación que la tecnología está propiciando de manera tan acelerada. ¿Y en cuanto a los ciuda- 
danos?. Por supuesto que también notan el peso que la tecnología va adquiriendo en su ocio y trabajo. Pero, ¿lo sienten de manera positiva?

Hay varias visiones que, si bien casi nunca se presentan en estado puro, sí forman tendencias que empapan el cuerpo social y que frecuentemente vemos reflejadas en la opinión pública:

\section{a) Determinismo tecnológico}

Según lo que comúnmente se entiende como determinismo tecnológico, el desarrollo de la tecnología sería autónomo y lineal, al margen de la influencia de la sociedad o de cualesquiera de sus componentes. Es decir, mientras que la sociedad se transforma a impulsos de la tecnología, ésta resulta impermeable a los factores que configuran la realidad social.

Esta teoría tiene mucho predicamento, si bien casi nunca es presentada de manera explícita. Es una aceptación en muchos casos inconsciente, derivada de la vieja ficción del progreso infinito. Un buen ejemplo sería esa manía de calificar las épocas concentrando las características de un periodo de tiempo en un impacto tecnológico concreto: «era espacial», «sociedad de la información», «siglo del automóvil», etc.

\section{b) Utopismo tecnológico}

Es la versión radical del determinismo tecnológico. Mientras que éste, aun subordinando el desarrollo social al impacto tecnológico, tiene un afán primordialmente descriptivo y no desconoce necesariamente los peligros de la tecnología, el utopismo tecnológico se sustenta en la afirmación de que la tecnología sólo puede traer felicidad social y progreso. Es una derivación de la concepción utópica clásica, presente en nuestra cultura desde la República de Platón, la ínsula Utopía de Tomás Moro o la Nueva Atlántida de Francis Bacon.

Al utopismo tecnológico se le puede aplicar la misma crítica que a sus ilustres predecesoras: es una actitud conscientemente ciega ante la realidad social y humana, con esquemas conceptuales imposibles de llevar a la práctica. Igualmente, tiene un punto positivo, que es el impulso reformador hacia un mundo mejor: un poder latente que puede en la práctica llegar a cambiar la realidad en mayor o menor grado. 
En utopismo tecnológico está detrás del boom de la ciencia-ficción de los años 60 y 70, que tuvo amplia relevancia pública a través de películas de cine y televisión (como la famosa Star Trek, todo un compendio de exaltación de la tecnología). También se pueden encuadrar aquí muchos de los escritos que aparecieron a lo largo de los últimos años del siglo, como el muy conocido La Tercera Ola, de Alvin Tofler. Quizá el gran mantenedor actual de esta corriente de pensamiento es el Massachusetts Institute of Technology (MIT) y su principal predicador, Nicholas Negroponte.

\section{c) El pesimismo tecnológico}

Es la actitud opuesta al utopismo tecnológico. Según esta teoría, la tecnología sería culpable de la degradación medioambiental, de la deshumanización social y, en ciertos casos, incluso de ser el soporte fáctico de regímenes totalitarios. Frecuentemente se presenta unida a actitudes ecologistas, pacifistas o antisistema, con un discurso alrededor de la idea de la tecnología como creadora de necesidades superfluas. Otras veces, la tecnofobia se manifiesta con rasgos violentos; recordemos los movimientos «ludistas», que destrozaban las máquinas en las incipientes fábricas del inicio de la Revolución Industrial, o el reciente caso Unabomber. Y también tiene precedentes literariamente célebres: Un Mundo Feliz, de Aldous Huxley, y 1984 de George Orwell.

Quizá en este apartado, además, habría que hacer un hueco para incluir a teóricos del fin de la ciencia (ha habido y hay muchos en activo $^{6}$, aunque cueste creerlo), y a los defensores de planteamientos irracionales.

No podemos desconocer que el pesimismo tecnológico tiene actualmente un cierto arraigo social. La creación de ministerios u otros organismos públicos dedicados a la protección del medio ambiente puede ser considerado una respuesta (más o menos cosmética) a estas inquietudes.

Naturalmente, las tres visiones anteriormente descritas son extremas. La sociedad se mueve con pareceres más mediatizados. La preocupación existe, y ante la tecnología no se suele ser indiferente. Por eso se está imponiendo en Occidente la línea CTS anteriormente comentada. Parte de la base de la bondad de la tecnología y de su importante contribución al progreso social y al aumento de la calidad de vida de las personas. Pero no desconoce los desajustes que su desarrollo conlleva; más aún en estos tiempos donde la velocidad que 
ha tomado la evolución de la tecnología es manifiestamente mayor a la propia capacidad de adaptación de la sociedad. Y promueve fórmulas para que las empresas tecnológicas no descuiden estos aspectos, e incluso publiciten y presenten a la opinión pública sus actividades en este sentido. El modelo, incipiente aún en España, está consolidándose en otros países de nuestro entorno (Francia, Dinamarca), y cada vez es más frecuente ver memorias de responsabilidad corporativa elaboradas en paralelo a la memoria económico-financiera. Las empresas reportan a sus accionistas, pero también a todos los ciudadanos.

\section{La Tecnología a la defensiva}

"No existe ninguna disciplina (excepto la economía) que intente hacer que el mundo actúe como ella cree que debería comportarse. Pero, claro está, lo que el homo sapiens hace y lo que el homo economicus haría son frecuentemente cosas muy diferentes. Esto, sin embargo, no hace que el modelo básico esté equivocado, como sucedería en cualquier otra disciplina. Solo significa que se deberán tomar acciones para torcer al homo sapiens de conformidad con el homo economicus. De esta forma, en vez de ajustar la teoría a la realidad, se ajusta la realidad a la teoríà.

Esta cita es de Lester Thurow, conocido profesor del MIT, un autor y divulgador de éxito precisamente en el campo de la economía, que es $\mathrm{su}$ formación de origen y su dedicación. Por eso viene bien la cita: es una crítica desde dentro del frecuentemente incomprensible papel que está jugando la superestructura económica y financiera en nuestra sociedad.

Acotando el tema a nuestro campo de interés: se trataría de dilucidar si la tecnología está pagando culpas que no son suyas. Si el homo faber se relaciona con el homo economicus — su pareja de baile en la sociedad de la información- en pie de igualdad, o bajo sometimiento. $\mathrm{Si}$, en definitiva, la tecnología está sirviendo de excusa para justificar los errores que la economía comete en esta loca olimpiada de crecimiento $\mathrm{y}$ productividad con que hemos cerrado un siglo y abierto otro.

\section{a) El mito de la tecnología omnipotente}

Los tecnólogos en general y los ingenieros en particular somos -siempre hemos sido- los menos interesados en hinchar el globo del poder omnímodo de la tecnología. Un técnico puede ser optimista sobre la capacidad de generación de ideas innovadoras, o exigente respecto a 
la velocidad que se imprime al desarrollo de un nuevo producto. Pero sabe mejor que nadie que ni la inventiva puede tender a infinito, ni el ciclo de un producto puede hacerse igual a cero. La tecnología tiene sus tiempos, como todo en la vida.

No hace todavía mucho, las tecnologías se sucedían unas a otras sin presiones financieras ni regulatorias. Había abundancia de foros $\mathrm{y}$ organismos internacionales donde, de una manera paciente y democrática, se acordaban estándares y se establecían líneas comunes de trabajo entre países; siempre con una orientación al servicio público más o menos explicitada.

Ahora las cosas son distintas. Una fuerte presión para conseguir resultados rápidos ha sustituido a la necesaria maduración tecnológica. Los prototipos se prueban directamente ante el mercado, por lo que tienen que ser baratos; a veces, demasiado baratos. No se estandariza en común; antes bien, se impone como estándar el primer producto en salir o el que es capaz de canibalizar al resto. Se mata a la planificación (la liturgia del ingeniero) mientras se glorifica el pelotazo tecnológico. Y, sobre todo, se convierte la innovación tecnológica en una carrera que, como las olímpicas, se rige por el citius, altius, fortius. Y habría que añadir: más barato.

Véase, si no, lo ocurrido con el UMTS. Una tecnología clave, se mire como se mire, resultado natural de la evolución de la segunda generación, y cuyo camino había sido largamente preparado desde los años 80 por la UIT $^{7}$. Y de repente, de la noche a la mañana, se convierte en una estrella de la prensa de color salmón sin mediar razón técnica para ello. Eran los primeros meses del mítico 2000; en el pico del boom bursátil, cuando la burbuja estaba más inflada y casualmente ningún gurú de los cientos que pontificaban desde los medios de comunicación parecía estar de guardia. Entonces, los gobiernos de los principales países europeos iniciaron una carrera desenfrenada para ver quién estrujaba mejor a la gallina de los huevos de oro. Las empresas de telecomunicaciones, insólitamente capitalizadas, parecían un saco sin fondo en el que se podían meter las manos para sacarlas rebosando oro. En aquellos momentos, la falta de perspectiva -otros lo llaman codicia- de muchos gobernantes y un optimismo desmesurado sobre las posibilidades de la tercera generación se confabularon para organizar las subastas de las licencias sobre la base de unos precios disparatados: en el Reino Unido, la subasta proporcionó 37.000 millones de euros; en Alemania, 50.500. Italia y Francia pusieron en marcha el procedimiento cuando ya se barruntaba el fiasco. Aun así, los italianos recaudaron 12.000 millones, mientras Francia tuvo que suspender la subasta por el escaso, en su criterio, nivel de las pujas ${ }^{8}$. 
Es decir, operadores tan solventes como Vodafone o Telefónica pagaron miles de millones de euros por un simple papel que les decía que podían poner - a sus expensas - una red en el Reino Unido o Alemania y buscar - a su riesgo - clientes para llenarla de tráfico.

$\mathrm{Y}$ a todo esto, ¿dónde estaban entonces los ingenieros?. Pues asistiendo asombrados a los cantos de sirena de consultores, analistas y bancos de inversión. Cualquier lectura retrospectiva de los papers de aquella época no deja ninguna duda sobre quiénes atizaban el fuego... los mismos que tan bien supieron luego apartarse sin que se les llegara a chamuscar siquiera el fondillo.

Tres años después, el resultado está a la vista ${ }^{9}$. Los operadores congelaron aquellos proyectos $\mathrm{y}$, en muchos casos, han provisionado en sus balances gran parte del coste de las licencias, porque su valor de mercado es muy inferior al que en su momento tuvieron. Los fabricantes de equipos de telecomunicaciones facturaron este pasado 2002 la mitad de lo que ingresaron en el 2000, y las empresas del sector sufrieron su tercer año negro consecutivo, con una caída del 38,8\% de capitalización bursátil (-37,2\% en 2000 y .-30,36\% en 2001). Por mencionar lo que nos es más cercano, en el ámbito de la Unión Europea el sector de las telecomunicaciones apenas creció en 2002 un 4,9\%; la mitad que en 2001. Un crisis en toda regla, que está dejando cientos de miles de trabajadores del sector en el paro ${ }^{10}$. Y con un agravante: se ha descapitalizado y puesto en grave riesgo un sector, las telecomunicaciones, clave en el desarrollo económico. ¿Y no habíamos quedado en que para Europa era fundamental extender la sociedad de la información, para alcanzar el mismo nivel de crecimiento económico que Estados Unidos?. ¿Y no era precisamente la tecnología móvil el único aspecto de la sociedad de la información en el que Europa iba por delante de Estados Unidos y, por lo tanto, el que más merecía ser cuidado?.

Para los técnicos de las operadoras y fabricantes, ha sido como visionar una película de terror en la que no habían escrito el guión ni seleccionado el elenco; antes bien, se les había colocado de figurantes para luego culparles del fracaso de crítica, público y taquilla... y, finalmente, echarles del cine.

\section{b) El mito de la rentabilidad a cualquier precio}

Cualquiera puede apreciar -en el ambiente; en los medios de comunicación - una imparable tendencia a reducir el mundo a expresiones 
económicas y a valores dinerarios. Todo es mensurable económicamente. Por valorar, se ha llegado hasta a calcular lo que valdría en dólares la selva amazónica, o el conjunto de las lluvias en un continente, o la provincia de Navarra. Las discusiones machadianas sobre valor y precio ya no son pertinentes; ambos términos se usan indistintamente y no se suelen diferenciar. Este mundo es más fácil de entender y más cómodo de manejar si lo consideramos como un gran mercado. Todo es reducible a una relación cliente-proveedor. Se comprende, pues, que dentro de una propia empresa se hable de "cliente interno" para referirse a otro departamento con el que se tiene relación; o que en determinados ministerios llamen a los ciudadanos «clientes», pretendiendo con ello que los funcionarios se tomen más interés en atenderles. $\mathrm{Y}$ con este horizonte único del compro y vendo, ¿no es lógico que el beneficio sea la medida del éxito?.

Esta simplificación tiene, sin embargo, algún que otro inconveniente. Veamos, por ejemplo, la I+D. Desde hace muchos años se nos viene machacando, tanto a escala nacional como por la Unión Europea, con la importancia de este capítulo. La innovación ha pasado a ser una palabra mágica cuya sola mención tiene el poder de evocar un futuro esplendente. Está presente en todos los discursos y no falta en ningún papel oficial ${ }^{11}$.

Se predica, pues, mucho. Pero, ¿dar trigo?. Refirámonos al sector de las telecomunicaciones: la inversión en $\mathrm{I}+\mathrm{D}^{12}$, a pesar de tanta declaración de intenciones, está experimentando un ligero pero constante descenso. En los operadores mundiales tradicionales, se está dando una disminución real de los recursos dedicados a la $\mathrm{I}+\mathrm{D}$ en relación con los ingresos. Los criterios de rentabilidad ya mencionados han puesto en riesgo muchas de las actividades que anteriormente se consideraban dentro del cómodo concepto de servicio público. Esto se deja ver bien claramente si advertimos la muy distante actitud con que encaran estas actividades las empresas de nueva creación, como Vodafone, por más que su actual peso sea mayor que el de muchos de los operadores tradicionales. $\mathrm{Y}$ si en los últimos tiempos las cifras, en algunos casos, todavía parecían abultadas, es porque normalmente corresponden a la adquisición de compañías de alta tecnología; lo que, de acuerdo con la legislación norteamericana, es considerado como inversión en I+D. Este fue el caso de, por ejemplo, los 4.000 millones de dólares que MCI Worldcomm declaraba como $\mathrm{I}+\mathrm{D}$ en sus cuentas de 1998.

En paralelo, disminuyen los recursos para investigación básica. Los centros de $\mathrm{I}+\mathrm{D}$ han ido reduciendo este tipo de tareas en beneficio 
de la investigación aplicada, más rentable a corto plazo. Y es que la rentabilidad ha pasado de ser una deseable aspiración a considerarse objetivo único, so pena de cierre de las actividades. En esas circunstancias, las unidades de $\mathrm{I}+\mathrm{D}$ se ven obligadas a reorientar su planteamientos buscando, en primer lugar, la suficiencia económica. Lo cual obliga a reestructurar la organización y el modo de trabajo, enfocándolos más hacia el cliente que hacia los planteamientos tecnológicos tradicionales. De este modo, el experto en $\mathrm{I}+\mathrm{D}$ dedica la mayor parte de su tiempo a apoyar la labor de las unidades comerciales de la empresa matriz, siendo una especie de guardaespaldas técnico del comercial de turno en su relación con el cliente. Y, en el extremo, se abren nuevas líneas de negocio que nada tienen que ver con la investigación, tales como gestión de fondos capital riesgo, consultoría estratégica o tecnológica. La conclusión es que el antiguo laboratorio de I+D pasa a asimilarse en todo a una empresa de desarrollo software.

En resumen, hemos encerrado a la I+D en el corsé de la rentabilidad. Los ingenieros pasan a ser comerciales ilustrados y a sustituir el osciloscopio por el estadillo de ventas. Se racanea en formación; se suprime participación en organismos internacionales a mayor gloria del EBITDA. Pero, sin que nadie parezca advertir la contradicción, se le siguen pidiendo resultados que no pueden nacer más que de una apuesta decidida por la investigación básica. Que es alérgica al corto plazo.

\section{c) El mito del ingeniero despilfarrador}

Cualquier ingeniero que haya escalado cierto nivel profesional ha tenido, con seguridad, múltiples ocasiones de soportar comentarios más o menos condescendientes, quizá paternales, otras veces insidiosos, sobre $\mathrm{su}$ incapacidad para entender las claves verdaderas del manejo de una empresa. Según este imaginario estereotipo, los ingenieros se empeñan no sólo en planificar -cosa tenida por absurda en este mundo tan cambiante-, sino que además (sobre error, contumacia) quieren concretar lo que habían planificado. Por eso resulta conveniente mantenerlos alejados de los verdaderos centros de decisión de las empresas $\mathrm{u}$ organismos ministeriales. Y dejarlos en el papel de consultores más o menos ilustrados.

¿Hay algo más raro que ver a un científico en los altos niveles del Ministerio de Ciencia y Tecnología; o a un médico a cargo de un hospital, o a un ingeniero naval dirigiendo un astillero?. En el credo triunfante, el empresario ideal incluso tiene a gala desconocer los se- 


\section{Tecnología y Sociedad. La nueva tarea del héroe}

cretos técnicos de la compañía que dirige. Él se limita a gestionar. Nada impide presidir una bodega siendo abstemio, o pertenecer al consejo de administración de un fabricante de ordenadores sin haber mandado en la vida un correo electrónico. El moderno gestor parece no necesitar el conocimiento especializado.

Esto no es de ahora, aunque quizá es ahora cuando más se ha exacerbado. Permítasenos un ejemplo a cuenta de uno de los más influyentes técnicos de la posguerra española, José Antonio Suanzes, ministro de Franco y creador del INI. Pues veamos cómo el eminente historiador de la economía Gabriel Tortella lo despacha en su libro «El desarrollo de la España económica. Historia económica de los siglos $X I X$ y $X X »$ :

El impulsor del INI y su presidente hasta 1963 fue José Antonio Suanzes, ingeniero naval (...). Las ideas básicas que presidieron la creación del INI fueron las siguientes: la industrialización de España era prioritaria y por lo tanto habia de lograrse a cualquier precio; el sector privado habia resultado incapaz de lograr esa industrialización por su falta de espíritu de iniciativa y quizá también por un mezquino afán de lucro (...). El esfuerzo del INI fue titánico pero cabe preguntarse con Schwartz y González ${ }^{13}$ si no fue arbitrista y despilfarrador. Suanzes tenía lo que estos autores han llamado "la mentalidad del ingeniero», buscando la producción por sí misma sin conciencia de los costes comparativos (...). En definitiva, el INI de la época heroica, es decir, de la presidencia de Suanzes, forjó una industria básica, pero con una debilidad fundamental: su falta de competitividad (...).

Ya ven, "mentalidad del ingeniero», para estos respetables catedráticos, equivale a inconsciencia económica y desprecio por la competitividad... así nos consideran, y de este prejuicio todavía muchos se alimentan.

Claro que siempre hay desquite. No con textos de ahora, que en esto también domina el pensamiento único, pero sí de hace poco menos de un siglo. El vengador de los ingenieros es Thorstein Veblen ${ }^{14}$, economista y sociólogo norteamericano de origen escandinavo, hoy comprensiblemente (enseguida se verá por qué) olvidado. A Veblen se le considera fundador del institucionalismo ${ }^{15}$, una corriente que tuvo cierta influencia en Estados Unidos a lo largo del pasado siglo, especialmente en los años 30, tras la depresión. Pero aquí nos interesa el aspecto hipercrítico, sarcástico y vehemente hasta la agresividad de Veblen, sus diatribas contra los financistas y sus teorías, que hoy suenan extraordinariamente provocadoras. Para Veblen, el técnico representaba la racionalidad en la empresa, el orden y la profesionalidad; mientras 
que el financiero era el símbolo de lo superfluo, cuando no del interés egoísta y la mala administración. En una de sus más conocidas obras, Engineers and the price system, llega a proponer el aislamiento de los financistas, a los que considera saboteadores del proceso productivo, y su reemplazo por técnicos.

La lectura de los textos de Thorstein Veblen es un bálsamo para la autoestima del ingeniero. Haría bien el Colegio o alguna otra institución profesional en costear la reedición de sus libros en una de esas colecciones de autoayuda, ahora tan en boga.

\section{Conclusión}

Hasta aquí, entre bromas y veras, hemos llegado dejando unas cuantas cosas claras (y muchas más oscuras). Pero si hay que resumirlas en una, diríamos que la tecnología ha demostrado un inmenso potencial trasformador. Es una obviedad, desde luego. Pero no lo son sus consecuencias. Como señalaba el profesor norteamericano Melvin Kranzberg, fundador de la Society for the History of Technology, en una de sus seis conocidas leyes ${ }^{16}$, la tecnología no es buena ni mala; pero tampoco neutral.

En esta línea, no queda más remedio que referirse al principal problema con el que la tecnología tendrá que lidiar obligatoriamente: el desafío del crecimiento infinito. Habrá muchos otros, pero sin duda éste será el mayor.

Una de las cosas que los técnicos entendemos más difícilmente, quizá porque nos tomamos las matemáticas en serio, es el culto al crecimiento que nuestra sociedad practica sin ninguna reserva. Hoy día se considera verdad revelada que hay que ir a por un $5 \%$ o más de crecimiento anual (en lo que sea). Equivale a un sobresaliente en gestión. Un $4 \%$ sería notable. El $3 \%$ es, según y cómo, aprobado. El $2 \%$ ya empieza a ser sospechoso de suspenso, aunque con posibilidades de recuperación. Un $1 \%$ es definitivamente una cifra poco presentable y una demostración de escasa habilidad en la gestión. Y crecimiento cero es para meterse debajo de la mesa. Estos porcentajes nos asaltan todos los días desde los diarios, la radio y la televisión, aplicados a multitud de temas: el PIB, la producción de tal o cual equipamiento, la recaudación de algún servicio... Se mencionan con toda la alegría del mundo, aunque a algunos nos desazonan bastante. $\mathrm{Y}$ no porque no creamos en el progreso ni confiemos en mejorar nuestro ya alto estándar de vida. Es que la fiesta no puede durar ad infinitum. Y 
quizá convendría pensar en dosificar la diversión antes de que se apaguen las luces bruscamente ${ }^{17}$.

La Comunidad de Madrid, por poner un ejemplo de moda, tenía un $1 \%$ de suelo urbano (contando la capital y el resto de núcleos de población) hacia 1950. Hoy estaría en torno al $10 \%$ el terreno cubierto por cemento y el asfalto. No está mal en apenas medio siglo, y eso que se excluyen las modificaciones de inmuebles urbanos preexistentes y la multiplicación de las alturas de los edificios.

Pues bien, imaginemos un candidato muy modesto que en una de estas elecciones nos prometiera crecer apenas un $1 \%$ anual (acumulativo, naturalmente). Las dichosas matemáticas nos dicen que un siglo después habría más del doble de suelo urbano e infraestructuras del que hoy hay. Si otro candidato, más entonado, nos promete un crecimiento de un 2\% anual, el año 2100 dejaría una Comunidad de Madrid con un $40 \%$ del suelo urbanizado. Crecer al ritmo del 3\% anual nos llevaría al $80 \%$ del terreno cubierto de civilización. Y crecer al $4 \%$ anual tendría como consecuencia ocupar el $140 \%$ del territorio de la Comunidad... con lo que las macetas pasarían a considerarse espacios protegidos, si no parques naturales. La pregunta surge sola: ¿cómo se puede manejar esto?. No hay respuesta, o más bien hay una: ya lo solucionará la tecnología.

Otro ejemplo menos castizo: el Protocolo de Kioto. Un acuerdo de 1997 por el que determinados países se comprometen a soltar en el 2012 el 95\% de los gases tóxicos y de efecto invernadero que ya emitían en 1990. (Entre paréntesis: no parece que sea un empeño muy exigente; más bien, bastante timorato, y aun así, cuenta con el expreso rechazo de la principal potencia contaminante, que escupe por sí misma el $30 \%$ de los gases de este mundo).

Pero una vez más las matemáticas ponen a todos en su sitio. Si desde 1990 se sigue creciendo económicamente (ergo, energéticamente) un, digamos $2 \%$ anual acumulativo, para el 2012, el mundo industrial estará produciendo cerca de un $60 \%$ más de bienes y servicios que en 1990 . Y no se puede pretender alcanzar un nivel 160 de producción en 2012 (siendo nivel 100 el de 1990) expulsando únicamente 95 de contaminantes.

En resumen, que este Protocolo es un ejemplo, otro más, de cómo la economía le pasa el muerto a la tecnología: prevé disminuir las emisiones (tarea de los ingenieros), pero no la producción de bienes (tarea de los economistas). Y en este punto hay que preguntarse dónde está el ingeniero que se comprometa a mejorar en un $80 \%$ la eficiencia de los cerca de mil millones de motores de combustión que hoy funcionan en el planeta. 
En este pésimo guión que estamos escribiendo todos los días, al técnico le ha tocado hasta ahora el papel de Cenicienta. Pero cuando la quimera del crecimiento infinito se derrumbe, no le quedará más remedio que envolverse con los ropajes del héroe, porque revertir el proceso va a ser poco menos que una tarea homérica.

Lo cual nos da pie a cerrar con una preciosa leyenda de nuestra mejor tradición clásica. Platón nos la cuenta en el Protágoras: Prometeo, creador del linaje humano, enseñó la habilidad técnica a los hombres, aunque no a todos. Enseguida los propios dioses se dieron cuenta de los efectos perniciosos de este desequilibrio, y decidieron enviar a Hermes para que distribuyera, esta vez a todos por igual, el sentido de la moralidad y de la justicia. De este modo, los logros de la técnica, aplicados con criterios éticos, habrían de beneficiar a la sociedad entera.

Los Olímpicos tenían razón. Los logros y los fracasos de la tecnología son responsabilidad exclusiva de los técnicos. Pero su buena aplicación, adecuada dosificación y equitativa distribución nos compete a todos.

\section{Notas}

1 Este texto es un resumen de la ponencia dictada en el seminario Tecnología, Sociedad y Mundo Laboral, dentro de los Cursos de Verano 2003 de la Universidad Complutense (El Escorial-Madrid).

2 Una investigación de 1989 de la revista Nature concluía en que sólo un $10 \%$ de la población se podía considerar científicamente educada.

3 Teólogo francés, su visión de la tecnología es pesimista.Considera que el estilo de vida que la tecnología ha impuesto corrompe los valores morales y llevará a la destrucción del modelo de sociedad que hasta ahora conocemos.

$4 \mathrm{Su}$ texto más conocido sobre este tema es La Pregunta por la Técnica.

5 Hay al menos una edición en español, de Emecé Editores S. A. (Buenos Aires).

$6 \mathrm{Ha}$ tenido cierta relevancia el biólogo de origen alemán pero residente en $\mathrm{Ca}$ lifornia Gunther S. Stent, autor del libro The Coming of the Golden Age: a View of the End of Progress, publicado en 1969, donde se sostenía que el acelerado desarrollo de la ciencia y la tecnología iba a provocar su colapso en un plazo breve, por la creciente complejidad de los temas y la poca disposición de la sociedad a costear su tratamiento.

7 La historia del UMTS (Sistema Universal de Telefonía Móvil) arranca en la temprana fecha de 1985, cuando el servicio celular, aun en su versión analógica, estaba prácticamente inédito. En aquel momento, la Unión Internacional de Telecomunicaciones (UIT) ya definió unas primarias características del sistema y, lo que es más importante, reservó el rango de frecuencias donde alojarlo. Lo llamó FPLMS (siglas en inglés de Futuro Sistema Público de Telecomunicaciones Móviles Terrestres) y más tarde, IMT-2000.

8 España, en este sentido, adoptó una política mucho más coherente que la de otros países comunitarios. Licitó mediante un modelo "beauty-contest» o concurso de 


\section{Tecnología y Sociedad. La nueva tarea del héroe}

méritos, con unos cánones sensiblemente por debajo de los que en ese momento se aplicaban en el Reino Unido, Alemania o Italia.

9 Naturalmente, la causa del desplome del sector a partir de marzo de 2000 no fueron sólo las licitaciones UMTS. También influyeron de manera decisiva los errores en las expectativas de demanda de las nuevas redes y servicios; la adulteración de los resultados de algunas empresas y el calentamiento bursátil que se generó tras la crisis asiática.

10 Sólo en telefonía fija y entre las operadoras "incumbentes" europeas, se calcula una pérdida de 100.000 empleos, el $20 \%$ de los puestos de trabajo existentes en el 2000.

11 A la fecha en que se escribían estas páginas se conoció que el presidente de la Comisión Europea, Romano Prodi, había presentado -inadvertidamente, según la prensa - un informe que recomienda la creación de una Agencia Europea de Investigación y Desarrollo.

12 El informe de la Fundacón COTEC presentado en junio de 2003 precisa que en España la inversión en $\mathrm{I}+\mathrm{D}+\mathrm{i}$ no llega al $1 \%$, la mitad de la media de la UE. Francia es el 2,18 \% y Alemania el 2,49\%. El objetivo fijado en el Consejo Europeo de Barcelona (marzo 2002) para el 2010 es del $3 \%$.

13 Tortella cita aquí el libro "Una historia del Instituto Nacional de Industria 1941-1976", escrito por Pedro Schwartz y Manuel Jesús González y publicado por la editorial Tecnos en 1978.

14 Thorstein Veblen (1857-1929). Estudió filosofía en Yale y posteriormente economía. Sus principales obras son The Theory of the Leisure Class (1899) y The Engineers and the Price System (1921).

$15 \mathrm{El}$ institucionalismo es una doctrina extraordinariamente ecléctica que fue incorporando a lo largo de todo el siglo XX norteamericano a economistas de muy distinta condición, pero unidos por el hilo común de la crítica al neoclasicismo y la creencia en la importancia de relacionar y abrir la economía a otras disciplinas. Además de Veblen, otros institucionalistas reconocibles serían Wesley Mitchell y John Commons. Más recientemente, también se ha relacionado a John Kenneth Galbraith con esta línea de pensamiento.

16 El profesor Kranzberg identificó en los años 50 las seis leyes que se debían seguir para abordar el estudio de la historia de la tecnología: 1) La tecnología no es buena ni mala; ni neutral. 2) La invención es la madre de la necesidad. 3) La tecnología viene en paquetes grandes o pequeños. 4) A pesar de que la tecnología puede ser un elemento primordial en muchos asuntos públicos, los factores no técnicos tienden a imponerse en las decisiones de política sobre desarrollo tecnológico. 5) Toda historia es relevante, pero la historia de la tecnología es la más relevante. 6) La tecnología es una actividad humana, y por lo tanto también lo es la historia de la tecnología.

17 El PIB es un indicador pésimo para medir el progreso, porque engloba todas las actividades, incluidas las dañinas. Por ejemplo, la catástrofe del Prestige con seguridad ha hecho crecer el PIB gallego.

18 Por comparar, el PIB de EE.UU. creció un $4 \%$ de promedio entre 1996 y 2000, y la zona euro un 2,6\%. Como China pasó del $8 \%$ y la India del $6 \%$, el promedio mundial para esos años es del 3,9\%. Entre 2001 y 2003 las previsiones bajan mucho, pero aun así se mantienen en el $2,8 \%$ de crecimiento promedio del PIB mundial. 